\title{
Saving the world
}

\author{
A long and almost uncrossable distance separates fundamental plant research carried out predominantly \\ in rich countries, and the production of better crops in the fields of poor farmers from developing regions. \\ A unique network of international organizations involved in global agriculture helps bridge that chasm.
}

It all started in a broken down and semiabandoned research field station in Mexico in 1943. Faced with waves of devastating wheat stem rust disease, the rural country started a programme of agricultural cooperation with its richer neighbour, the USA, financed by a small grant from the Rockefeller Foundation. This collaboration brought to Mexico a young plant pathologist from Iowa, by the name of Norman Borlaug.

During his twenty years in Mexico, he was seen in the fields practically every morning, talking with local farmers about their needs and devising innovative wheat breeding programmes to solve the current problems. He wrote that agriculture was not an "idyllic state of harmony between humankind and nature", but a "struggle between the forces of natural biodiversity and the need to produce food". His international team of students, researchers and technicians brought the scientific knowledge of crop breeding to the local farmers who needed it the most, because a good harvest was the key to their survival.

Borlaug's novel strategies quickly started to produce results: stem rust resistance, higher yields with adequate use of nitrogen fertilizer, photoperiod insensitivity, broader climate range, and lodging-resistant semidwarfs. The new seeds were distributed widely. Yields and national wheat production exploded. Soon Mexico was self-sufficient for wheat production. This success was the spark that started the green revolution, which would expand to new countries and other staple crops like rice and maize. In 1970, Borlaug received the Nobel Peace Prize for his work on food security through improved agriculture and the creation of better crops.

To cement this success, the US-Mexico pilot cooperation programme for wheat was reorganized into an international non-profit organization called CIMMYT (International Maize and Wheat Improvement Centre). Another based in the Philippines was created to focus on rice research (IRRI, the International Rice Research Institute) and was instrumental in transferring the wheat accomplishments to rice. These were new types of crop-specific international organization, started in the midst of the UN and its food security arm the FAO.
They were created around the post-war hope that international cooperation could prevent war and decrease the historical tendency of mankind to destroy itself by every means possible. Multinational, but based in the countries where their work is needed most, and close to the centre of origin of the crops and the wild relatives. At the vanguard of international scientific research, but able to understand the needs of local small farmers. Financed by rich countries to help mostly poor farmers and make them self-sufficient. With the education of international students, researchers and technicians as a priority, to spread the knowledge in a virtuous cycle.

There are now fifteen of these centres. The CIP in Peru focuses on potato and sweet potato. CIAT in Colombia is about tropical agriculture and grain legumes such as beans. The ICARDA had to move from Syria to Lebanon - an unfortunate reminder that international cooperation cannot always stop wars - and specializes in dry region agriculture with crops like chickpea and lentil; while the ICRISAT in India works in semi-arid crop improvement and focuses on locally important crops such as millet and sorghum. CIFOR in Indonesia targets forests, and AfricaRice's name is self-explanatory. Bioversity International in Italy works to safeguard plant biodiversity and, between other missions, maintains the world's largest banana germplasm collection. Collaborations between the organizations are encouraged to build multidisciplinary transversal projects such as the broad 'Roots, Tubers and Banana' research programme.

These 15 independent and non-profit centres are grouped under the Consultative Group on International Agricultural Research (CGIAR), founded in 1971. The three goals of this organization are simple to write but difficult to attain: to reduce poverty, to improve food security, and to improve natural resources. Individually and collectively they have produced countless impressive stories of education and technology dissemination: biofortified beans to fight anaemia in Rwandan women, orange sweet potato against vitamin A deficiency in sub-Saharan Africa, disease control strategies with banana farmers worldwide, improved coffee supply chain in Colombia, sustainable cassava processing in Vietnam, high-yielding finger millet in Kenya, and many more. All of which translates into fewer poor and malnourished people, and increased future potential unlocked with now-healthy children without stunted growth or vitamin deficiency, staying longer in school. Why aren't these uplifting stories front page news on daily newspapers?

At Nature Plants we're trying to play a part in disseminating applied crop science successes. In April we published a study about rational breeding in rice; the seeds from the created lines have been deposited at IRRI and are available to any scientist ${ }^{1}$. Last month's issue also contained a new technology to control flowering time in rice with practical applications in various cereals ${ }^{2}$, as well as a Comment on agrobiodiversity and sustainability co-written by a CIAT researcher ${ }^{3}$. This month we have more rice research about the role of the GW5 grain size locus, important for yield (article no. 17043). We also have an elegant study about how to use the grass Setaria viridis as a small-genome $\mathrm{C}_{4}$ model for maize, to accelerate gene discovery in the crop (article nos 17054 and 17060). The global significance of rice, maize and wheat is in no doubt, together they feed half of humanity.

In the teeth of the double threats of population growth and climate change, the work of the CGIAR and its fifteen specialized centres is more essential now than ever. International collaborations and increased partnerships between government, public institutions, private companies, and philanthropic organizations, were desperately needed to fuel the green revolution. They are still needed today and tomorrow will bridge the gap between breakthroughs in laboratories, including GMO and edited crops, and farmers fields in countries where hunger, poverty and subsistence farming are the norm. As Borlaug wrote, "Fundamentally, the issue is whether small-scale farmers of the developing world also have a right to share the benefits of biotechnology."

\footnotetext{
References

1. Zeng, D. et al. Nat. Plants 3, 17031 (2017).

2. Okada, R., Nemoto, Y., Endo-Higashi, N. \& Izawa, T. Nat. Plants 3, 17039 (2017).

3. Zimmerer, K. S. \& de Haan, S. Nat. Plants 3, 17047 (2017)
} 